\title{
Individual and community-level factors influencing optimal breastfeeding: A multilevel analysis from a national survey study in Ethiopia
}

\section{Amanuel Hagos}

Mekelle University College of Health Sciences

Mache Tsadik

Mekelle University College of Health Sciences

Abate Bekele

Mekelle University College of Health Sciences

Afewerki Tesfahunegn ( $\square$ afom.te@gmail.com )

Mekelle University College of Health Sciences https://orcid.org/0000-0002-1325-5796

Research article

Keywords: Ethiopia Demographic Health Survey, optimal breastfeeding, multilevel analysis

Posted Date: August 31st, 2019

DOI: https://doi.org/10.21203/rs.2.13720/v1

License: (9) This work is licensed under a Creative Commons Attribution 4.0 International License. Read Full License

Version of Record: A version of this preprint was published at PLOS ONE on April 29th, 2021. See the published version at https://doi.org/10.1371/journal.pone.0241428. 


\section{Abstract}

Background Optimal breastfeeding is critical for healthy growth. Despite this about 820,000 children and 20,000 women lost due to inappropriate breastfeeding each year globally. In Ethiopia, about 50,000 children lost related to malnutrition. Of these, about $18 \%$ of child death is contributed by poor breastfeeding habit. Many studies reported the individual-level factors; however, little is known about the determinants of breastfeeding at the hierarchical level. Therefore, this study aimed to identify factors associated with optimal breastfeeding among children age 0-5 month in Ethiopia using multilevel analysis.Methods A five-year representative survey study was conducted to assess the determinants of optimal breastfeeding among 1,087 children aged 0-5 months using the 2016 Ethiopian Demographic and Health Survey data (EDHS). Both bivariate and multivariable multilevel logistic regression analysis were done to identify significant explanatory variables. Fixed effect and random effect were done to estimate the association between the dependent and explanatory variable and to measure the variation explained by the higher level respectively.Results Among the total of 1,087 children, only $45.4 \%$ of optimally breastfed. Children aged $4-5$ months (AOR $=0.19 ; 95 \% \mathrm{Cl}$ : $0.12-0.27)$, children from richest wealth index (AOR=2.87; 95\% Cl: 1.53- 5.43), children born through cesarean section and residing in Afar region were found significantly associated with optimal breastfeeding. The random-effects showed that the variation between communities was statistically significant.Conclusion Both individual and community level factors play a significant role in shaping optimal breastfeeding. Future strategies and health interventions should target individual and community level factors that enhance optimal breastfeeding.

\section{Background}

Optimal Breast Feeding (OBF) is breastfeeding within one hour of birth (early initiation of breastfeeding), breastfed exclusively for the first six months of life and continues to be breastfed up to two years of age. Starting at six months, breastfeeding is combined with safe, age-appropriate feeding of solid, semi-solid and soft foods [1]. OBF protects the two leading causes of child death pneumonia and diarrhea. Other than this, OBF builds child immune system that helps to prevent overweight/obesity and enhances mental development and bonding between mother and child [2-4].

Breast milk makes the world healthier and exclusive breastfeeding can save 520,000 children's lives over the next 10 years [3-5]. Breastfeeding is cost-effective to ensure the well-being of the citizen and plays a role in poverty reduction $[1,6]$. However, about 68 countries have breastfeeding rates of below $50 \%$ in 2016 globally. Moreover, about $20 \%$ of child deaths each year are attributable to poor breastfeeding habits $[4,7]$.

In Sub Saharan Africa breastfeeding is estimated to be $41 \%$ and with the overall prevalence of initiation of breastfeeding within one hour and exclusive breastfeeding of $52.83 \%$ to $49.17 \%$ respectively [8]. In Ethiopia, the prevalence of exclusive breastfeeding is $52 \%$ and about one-third of babies do not receive breastfeeding within one hour of birth and only one-third of children 4-6 months old received exclusively 
breastfeeding [4]. One study in south Ethiopia also reveals that the prevalence of OBF was found that $37.3 \%$ [9].

There are about 50,000 child deaths a year related to malnutrition. Of these, about 9,000 (18\%) deaths are linked to poor breastfeeding habits. Moreover, about $38 \%$ of children under age five are stunted, $10 \%$ are wasted, and $24 \%$ are underweight [10].

Optimal breastfeeding can be affected by giving the child an early additional food or fluid which is about 28.92\% in Ethiopia [10]. If optimal breastfeeding wasn't achieved, the child can suffer from irreversible growth and die from diseases like diarrhea and pneumonia [4].

The previous studies in Ethiopia mainly concentrated on individual-level factors and analysis was made using ordinary logistic regression. However, as EDHS data has a hierarchical nature, a multilevel logistic regression analysis is preferred to consider the individual and community level factors simultaneously. Thus, this study aimed to identify factors associated with optimal breastfeeding among children age 0-5 month in Ethiopia.

\section{Methods}

Study Area, design and population

The study was conducted in Ethiopia located in the horn of Africa with a total population of about $105,350,020$. The country has 9 Regional States and two city administrations with over 80 different ethnic groups. About $65 \%$ of rural households in Ethiopia consume the World Health Organization's minimum standard of food per day (2,200 kilocalories), with $42 \%$ of children under 5 years old being underweight [21]. This study employed a cross-sectional study design to assess the determinants of OBF among a total of 1,087children aged 0-5 months in EDHS 2016 selected enumeration areas [22]. All women of the reproductive age group residing in the selected households were eligible to be interviewed. All the data related to all children with age 0-5 month in the EDHS 2016 were included in this study.

\section{Sample size determination and procedure}

The sample of 1,087 children's from the 2016 EDHS was designed to provide estimates of key indicators for the country. Each region was stratified into urban and rural areas yielding 21 sampling strata.

Samples of enumeration areas were selected independently in each stratum in two stages. In the first stage, a total of 645 enumeration areas (202 in urban areas and 443 in rural areas) were selected. In the second stage of selecting a fixed number of 28 households per cluster were selected with an equal probability systematic selection from the newly created household listing.

Data source, data extraction, and management

The EDHS, 2016 was a nationally representative large scale dataset conducted by the central statistical agency (CSA) in collaboration with the ministry of health from January 18,2016 , to June 27,2016 . Data 
set was obtained by attaching the title and significance of the study. Then, after receiving permission for registration data set was downloaded at www.measuredhs.com from Measure DHS website. This was followed by extraction of the wide range of information about potential individual and community level factors from the EDHS 2016; particularly from the dataset of child record including child mortality, nutrition, maternal, child health, family planning, and other reproductive health issues.

Variables and measurements

Optimal breastfeeding: refers to a child less than six months old who had received breastfeed timely (within one hour of birth) and had no intake of food/fluids other than breast milk for the first six months (i.e. EBF).

In this study, the dependent variable was optimal breastfeeding (OBF) practices. In the regression analysis, OBF practice was coded ' 1 ' while ' 0 ' was coded for non-OBF practices. The independent variables considered were: age, residence, educational status, marital status of mothers, household income, occupation, family size, sex of the infant, place of delivery and ante-natal and post-natal service utilization. The age of mothers was categorized as 15-19, 20-24,

25-29, 30-34and 35-39.

The younger age group was taken as a reference population in the regression analysis. The religion of mothers was coded as ' 0 ' for Christian and ' 1 ' for Muslim. Urban and rural residences of mothers were coded as ' 0 ' and ' 1 ' respectively. Regarding the educational status of parents, those who could not read and write were coded as ' 0 ' while the rest were coded as ' 1 '. Mothers who were housewives were coded ' 0 ' while farmers and employed mothers were coded ' 1 '. The lowest household income was coded ' 0 ' while the other two levels were coded ' 1 '. Mothers who received infant feeding counseling and delivered in a health institution were coded as ' 0 ', while those who did not receive those services were coded as ' 1 '. Age of the child was categorized as less than 2 months, 2-3 months and 4-5 months.

Data analysis

The extracted dataset was cleaned, coded, and analyzed by using Stata version 13.1 and excel was used. After generating the new variables EIBF and EBF the outcome variable was also generated from both EIBF and EBF. EDHS sample was not self-weighted because of non-proportional allocation. Therefore, sampling weights was used to make the sample representative of the entire population.

Frequency and percentage was used to report categorical variables, while median was used to report non parametric continuous explanatory variables. Bivariate analysis was performed to examine the association between optimal breastfeeding and each individual (level 1) and community level factors (level 2) at $p$-value less than or equal to 0.25 . Finally, multivariable multilevel logistic regression analysis was performed to estimate the adjusted odds ratios for both level and to estimate the extent of random variation between communities at $p$-value less than 0.05 and confidence interval $95 \%$ [23]. 


\section{Model specification}

Four models containing variables of interest was fitted using xtmelogit command.

Model I (empty model): $\log \left(\frac{y_{i j}}{1-y_{i j}}\right)=\beta_{0 j}+u_{0 j}$

Where, $\log \left(\frac{y_{i j}}{1-y_{i j}}\right)$ is the probability of optimal breastfeeding $\beta_{0 j}$ is the regression intercept; $u_{j}$ is

residuals at community level

This is the first step in the multilevel model analysis fitted without covariates to test random variability in the intercept and to estimate the intra-class correlation coefficient (ICC). The empty model enables the researcher to verify if the random effects at the community level are large enough to justify assessing random effects at the community level. When ICC is close to zero most of the variation is explained by lower level that means there is no variation between group effect and also if the ICC is close to one most of the variation is explained by higher level that means there is no variation between lower level effect [22]. However; the minimum value or cut point of ICC is 0.1 or $10 \%$ [23].

Model II: This model examines the effects of individual characteristics on optimal breastfeeding. These individual level factors which were statistically significant at the bivariable analysis were included in this model. The equation is as follows: $\log \left(\frac{y_{i j}}{1-y_{i j}}\right)=\beta_{0 j}+$ $\beta_{1 j} X_{1 i j}+\ldots \beta_{n j} X_{n i j}+u_{n j}+e_{i j}$

Where; $\log \left(\frac{y_{i j}}{1-y_{i j}}\right)=$ is the dependent variable $\beta_{0 j}=$ is intercept, $B_{1 j}=$ regression coefficient $\mathrm{X}_{\mathrm{ij}}=$ level-1 predictor ${ }_{\mathrm{ij}}$ - is the random error [21]

Model III: This model was used for community level variables which were significant at the bivariable analysis. The equation looks as follows:

$\log \left(\frac{y_{i j}}{1-y_{i j}}\right)=\beta_{0 j}+\beta_{1 j} Z_{1 j+\ldots} \beta_{n j} X_{n j}+u_{n j}+e_{i j}$

Where; $\log \left(\frac{y_{i j}}{1-y_{i j}}\right)=\beta_{0 j}$ mean intercepts, $\beta_{1 j}$ regression coefficients $Z_{\mathrm{ajj}} \mathrm{is}$ community level explanatory variable and $\mathrm{u}_{\mathrm{nj}}=$ is residual error at community level

Model IV (Mixed model or final model): this model includes both the individual and community level characteristics of optimal breastfeeding which were statistically significant and it allows to measure the effect of both individual and community characteristics simultaneously.

The final two models were expressed as: $\log \left(\frac{y_{i j}}{1-y_{i j}}\right)=\beta_{0 j}+\beta_{1 j} X_{1 j}+\beta_{1 j} Z_{1 j+\ldots}+u_{0 j}+e_{i j}$ 
$\beta_{0 j}$ is the intercept $\beta_{1}, \beta_{2}, \beta_{n}$ are the regression coefficients estimate the data $X_{1 j}, X_{2 j}, X_{n j}$ are covariates at individual level, $Z_{1 j}$ covariate at community level--- [21].

\section{Parameter estimation methods}

Maximum likelihood estimators (MLE) maximize the probability of finding the sample data that actually found. The Maximum Likelihood (ML) was used to assess the goodness of diagnostic test. This estimator includes both the regression coefficients and the variance components in the likelihood function [24].

In the multilevel models the measures of association (fixed-effects) estimates the associations between likelihood of children optimally breastfeed and various explanatory variables expressed as Adjusted Odds Ratio (AOR) with their 95\% Confidence Intervals (Cls). The measures of variation (random-effects) were reported as Intra-class correlation coefficient (ICC) ICC $=\sigma^{2} \mathrm{u} 0 /\left(\sigma^{2} \mathrm{u}_{0}+\sigma \mathrm{e}^{2}\right)$ where $\sigma \mathrm{e}^{2}=\pi^{2} / 3$ where the variance was explained by the higher level. The change in the community level variance between the empty model (Model 1 ) and the consecutive models $V_{\mathrm{e}}$ was expressed by Proportional Change in Community Variance (PCV) by using the formula PCV $=\left(\mathrm{V}_{\mathrm{e}}-\mathrm{V}_{\mathrm{mi}}\right) / \mathrm{V}_{\mathrm{e}}$, The ICC and PCV were calculated at each model with reference to null model using the above formula.

\section{Model diagnostic}

The effect of multicolliniarty between the predictor variables was checked using variance inflation factor (VIF) at cut off point of 10. Predictors having a VIF value of less than 10 indicate absence of Multicolliniarty [25].

\section{Model selection}

Akaike information criteria (AIC) were used to compare and check the goodness of fit of consecutive models. The AIC values for each model was compared and the model with the lowest value of AIC was considered to be better explanatory model fitting the data very well [22].

\section{Model accuracy}

The receiver operating character (ROC) curve were used to show in a graphical way the connection /tradeoff between sensitivity and specificity for every possible cutoff for a test or combination of tests and the area beneath the curve is often used as a measure of the predictive power (usefulness of a test) which indicates the greater the predictive power, the more bowed the curve. A model with no predictive power has area 0.5 ; a perfect model has area 1 . Lroc were used to examine the predictive ability of the model.

Ethical clearance 
Ethical approval was obtained from Mekelle University, College of Health Sciences Institutional Review Board (IRB) and approval to access the 2016 EDHS dataset was obtained from (web address: http://www.measuredhs.com), after making a request via DHS program website.

\section{Results}

\section{Description of individual and community level characteristics}

Among the total of 1,087 surveyed children, 493 (45.4\%) were optimally breastfeed. About $382(35 \%)$ of the children were in the age group of 4-5 months and 557 (51\%) were female children. About $214(60.6 \%)$ children below the age of less than 2 months were optimally breast feed. Optimal breast feeding was very low among mothers with educational status of secondary school and above (Table-1). Relatively, mothers from Afar and Somali regions reported low proportion of optimal breast feeding. There is no significant variation in proportion of optimal breastfeeding in the other community level variables (Table 2).

\section{Multilevel logistic regression analysis:}

In the final model, age of children, wealth index, delivery by c/section and region were found significantly associated with optimal breastfeeding. After controlling the potential confounders at the individual and community level factors, the age of children was negatively associated with optimal breastfeeding that showed children 4-5 months old were less likely to breastfeed optimally when compared to age less than two months (AOR=0.19; $95 \% \mathrm{Cl}: 0.12-0.27$ ). The odds of optimally breastfeeding were higher among children from richest wealth index compared to those from poorest wealth index (AOR=2.87; 95\% Cl: $1.53-$ 5.43). Optimal breastfeeding was less likely among children born with $\mathrm{C} /$ section as mode of delivery when compared to their counter parts ( $A O R=0.18 ; 95 \% \mathrm{Cl}: 0.07-0.51)$. Children born from mothers residing in Afar region were less likely to breastfeed optimally than children born from mothers from Addis Ababa (AOR=0.13; 95\% Cl: (0.02-0.92) (Table 4). The mean VIF value of 3.07 indicated the absence of collinearity between explanatory variables (Table 3 ).

The random effect in the final model showed that $51 \%$ of the variation in optimal breastfeeding across communities was explained by both individual and community level factors. Accordingly; the model with highest PCV (51\%) expresses the change in the community level variance very well. The subsequent decrease in the values of AIC on each model indicates that the final model AIC (1280.113) was the best explanatory model fitting the data very well (Table 4).

\section{Discussion}

The study aimed at identifying individual and community level factors that influence optimal breastfeeding among children $0-5$ months. Variables such as age of child, wealth index, delivery by $\mathrm{c} /$ section and region were found statistically significant predictors of optimal breast feeding. 
As shown in this study, the age of children was negatively associated with optimal breastfeeding. Children's 4-5 months were less likely to be breastfeed optimally when compared to age less than two months. Possibly, as the age of the child increases the practice of optimal breastfeeding decreases which is consistent with the studies in Ethiopia $[9,18]$. Similarly, studies in other countries like Tanzania, Zimbabwe and Nepal showed that the practice of optimal breastfeeding likely reduces with increasing age of children $[11,12,26]$. This might be related to the misunderstanding of mothers about the importance of optimal breastfeeding and initiation of additional food when the child's age increases. Likewise another possible explanation for less optimal breastfeeding may be related to the perception and cultural practice of mothers that breast milk production is insufficient for the child's growth $[26,27]$.

The current study on delivery by cesarean section has shown a negative association with optimal breastfeeding compared to children delivered without cesarean section. This finding is consistent with previous reports from different districts of Ethiopia and Tanzania $[9,12]$. The possible explanation can be related to the effects of anesthesia delaying the onset of lactation and some baby-unfriendly postoperative-care practices. During cesarean delivery more attention may be given to the mother, while the child feeding might be forgotten. Mothers might also be uncomfortable to breastfeed because of the pain experienced after surgery or take longer to recover from the effects of the anesthesia $[15,16]$.This might cause a longer delay in making their first contact with their child, and mothers might also find it difficult to achieve comfortable breastfeeding positions. In addition, children born by cesarean section might have respiratory distress. Hence, they are more likely to be taken to a newborn intensive care unit and physically separated from their mother $[14,17]$.

In this study, wealth index has a positive relationship with optimal breastfeeding. Children from richest wealth index were almost 3 times more likely to be optimally breastfeed compared to children from poorest wealth index. This finding is similar with the study conducted by Centers for Disease Control and Prevention and National Center for Health Statistics which indicates poor practice of optimal breast feeding among mothers in the poorest wealth index [28]. In contrast to this, other studies have shown that mothers with the poorest wealth index practice optimal breast feeding compared to the richest wealth index $[9,18,19,29]$. The low practice of optimal breastfeeding among the poorest could be linked with the lack of awareness, stressful living situation to overcome the hard of living [28]. Likewise, it can also be explained as mothers from the poorest index might consider themselves as producing inadequate breast milk that satisfy their child's demand which influences them to look for additional food.

Among the community level variables, region was found significantly associated with optimal breastfeeding. Children from Afar were less likely to optimally breastfeed than children from Addis Ababa. This is contextually similar to other studies conducted in Ethiopia, Nigeria and Nepal $[14,15,30]$. Mothers residing in towns and villages practice less optimal breastfeeding compared to those residing in larger towns and cities like Addis Ababa. The reason behind is those residing in larger towns and cities may have better access to health information and healthcare service. Besides, mothers residing in larger towns and cities may be less influenced by traditional and cultural practice than their counter parties. 


\section{Strengths And Limitations}

As this study was used nationally representative data, the study findings can be used to inform policy and program actions. In addition, this study applied multilevel modeling to accommodate the hierarchical nature of the EDHS data and to examine the extent of variations across communities. Despite the strengths, the data used for this analysis were from a cross sectional survey. As a result, only associations were examined and may not draw a true conclusion about causality and may increase also recall-bias. Also some important variables such as maternal beliefs, miss-conceptions and knowledge towards breastfeeding were not included.

\section{Conclusions}

The magnitude of OBF was low in this study. Regarding the predictors of OBF, both the individual and community level factors were found to be significantly associated. At the individual level; children's age, wealth index and mode of delivery were the factors that influence optimal breastfeeding. Among the community characteristics only region was found as a significant predictor of OBF. Thus, interventions to create awareness about the benefits of OBF should be implemented in areas where there is low practice of OBF. Moreover, Mothers delivered by CS should be assisted and counseled to breast feed their child within the recommended time by the care providers.

\section{Abbreviations}

AIC-Akaike Information Criteria, ANC-Antenatal Care, AOR-Adjusted Odds Ratio, Cl-Confidence Interval, CSA-Central Statistical Agency, EBF-Exclusive Breast Feeding, EDHS-Ethiopian Demographic Health Survey, EIBF, ICC-Intraclass Correlation Coefficient, IRB-Institutional Review Board, MLE-Maximum Likelihood Estimator, OBF-Optimal breast Feeding, PCV-Proportional change in Community Variance, ROC-Receiver Operating Character, and VIF-Variance inflation Factor

\section{Declarations}

Ethical approval and consent to participate

Ethical approval was obtained from Mekelle University, College of Health Sciences Institutional Review Board (IRB) and approval to access the 2016 EDHS dataset was obtained from (web address: http://www.measuredhs.com), after making a request via DHS program website.

\section{Consent for publication}

Not applicable

Availability of data and materials

Data are available from the corresponding author on reasonable requests. 


\section{Competing interest}

The authors declare that they have no competing of interest interests among themselves.

Funding

The study was funded by Mekelle University for the activities of data collection and data analysis

\section{Authors' contribution}

The authors' responsibilities were as follows; AH conceptualization, designed the research and ensured the quality of the data. AT, MT, and AB analyzed, interpreted the findings and drafted the manuscript. AT the corresponding author submitted the paper for publication. All authors reviewed the manuscript and approved the final version for submission.

\section{Acknowledgments}

We would like to thank Tigray regional health bureau. We have also a special thanks to Mekelle University and central statistical agency staffs.

\section{References}

1. UNICEF, Infant and young child feeding, 2018.

2. WHO, New guidance to promote breastfeeding in health facilities globally. Geneva, 2018.

3. Victora CG, Bahl R, Baros AJD, Franca GV, Horton S, Krasavec J et al. , Breastfeeding in the 21thcentury: epidemiology, mechanism, and lifelong effect. Lancet, 2016. 387(10017): p. 475-490.

4. UNICEF, The Investment Case for Breastfeeding: Nurturing the Health and Wealth of Nations, 2017.

5. UNICEF, Breastfeeding gives children the best start in life: the key for sustainable development. 2016.

6. Issaka Al, Agho KE, Renzaho AM., Prevalence of key breastfeeding indicators in 29 sub-Saharan African countries: a meta-analysis of demographic and health surveys (2010-2015) BMJ open, 2017 7(10): p. e014145.

7. Institute Ifpr, Global nutrition report 2016: From promise to impact: Ending malnutrition by 2030. International Food Policy Research Institute Washington, DC. 2016.

8. Belachew AB, Kahsay AB, Abebe YG, . Individual and community-level factors associated with introduction of prelacteal feeding in Ethiopia. Archives of Public Health, 2016. 74(1): p. 6.

9. Abageda M, Mokonen A, Hamdela B, Predictors of Optimal Breastfeeding Practices Among Mothers Who Have Less Than 24 Months of Age Children in Misha District, Hadiya Zone, South Ethiopia. Pregnancy and Child Health, 2015. 2(4).

10. Tewabe T, Mandesh A, Gualu T, Alem G, Mekuria G, Zeleke H, Exclusive breastfeeding practice and associated factors among mothers in Motta town, East Gojjam zone, Amhara Regional State, Ethiopia, 2015: a cross-sectional study. . International breastfeeding journal, 2016. 12(1): p. 12. 
11. Pandey S, Tiwari K, Senarath U, Agho KE, Dibley MJ, , Determinants of infant and young child feeding practices in Nepal: secondary data analysis of Demographic and Health Survey 2006. . Food and nutrition bulletin, 2010. 31(2): p. 334-51.

12. Victor R, Baines SK, Agho KE, Dibley MJ, Determinants of breastfeeding indicators among children less than 24 months of age in Tanzania: a secondary analysis of the 2010 Tanzania Demographic and Health Survey. BMJ open, 2013. 3(1): p. e001529.

13. Hoche S, Meshesha B, Wakgari N, Sub-optimal breastfeeding and its associated factors in rural communities of Hula District, southern Ethiopia: a cross-sectional study. Ethiopian Journal of Health Sciences, 2018. 28(1): p. 49-62.

14. Lakew Y, Tabar L, Haile D, Socio-medical determinants of timely breastfeeding initiation in Ethiopia: Evidence from the 2011 nationwide Demographic and Health Survey. International breastfeeding journal, 2015. 10(1): p. 24.

15. Berde AS, Yalcin SS, Determinants of early initiation of breastfeeding in Nigeria: a population-based study using the 2013 demographic and health survey data. BMC pregnancy and childbirth, 2016. 16(1): p. 32.

16. Ndirangu M, Gatimu S, Mwinyi H, Kibiwott D, Trends and factors associated with early initiation of breastfeeding in Namibia: analysis of the Demographic and Health Surveys 2000-2013. BMC pregnancy and childbirth, 2018. 18(1): p. 171.

17. Liben ML, Yesuf EM, Determinants of early initiation of breastfeeding in Amibara district, Northeastern Ethiopia: a community based cross-sectional study. International breastfeeding journal, 2016. 11(1): p. 7.

18. Tewabe T, Timely initiation of breastfeeding and associated factors among mothers in Motta town, East Gojjam zone, Amhara regional state, Ethiopia, 2015: a cross-sectional study. BMC pregnancy and childbirth, 2016. 16(1): p. 314.

19. Shifraw T, Worku A, Berhane Y, Factors associated exclusive breastfeeding practices of urban women in Addis Ababa public health centers, Ethiopia: a cross-sectional study. International breastfeeding journal, 2015. 10(1): p. 22.

20. Central statistical agency (CSA), Central statistical agency and ICF. 2016. Ethiopia Demographic and Health Survey 2016. Addis Ababa, Ethiopia, and Rockville, Maryland, USA: CSA and ICF, 2016.

21. Guo G, Z.H., Multilevel modeling for binary data. Annual review of sociology, 2000. 26(1): p. 441-62.

22. Boedeker P, Hierarchical Linear Modeling with Maximum Likelihood, Restricted Maximum Likelihood, and Fully Bayesian Estimation. Practical Assessment, Research \& Evaluation, 2017. 22(2): p. 2.

23. G, S., Choosing the best index for the average score intraclass correlation coefficient. Behavior research methods, 2016. 48(3): p. 994-1003.

24. Steenbergen MR, Jones BS, Modeling multilevel data structures. American Journal of Political Science, 2002: p. 218-47.

25. Craney TA, Surles JG. , Model-dependent variance inflation factor cutoff values. Quality Engineering, 2002. 14(3): p. 391-403. 
26. Pamela MT, Socio-demographic factors associated with exclusive breastfeeding among mothers with children less than six months of age in Zimbabwe, November 2015.

27. Jones JR, Kogan MD, Singh GK, Dee DL, Grummer-Strawn LM, Factors associated with exclusive breastfeeding in the United States. 2011.

28. R, P., Breastfeeding and Socioeconomic Status An Analysis of Breastfeeding Rates Among Low-SES Mothers, 2013.

29. Khan GN, Ariff S, Khan U, Habib A, Umer M, Suhag Z, et al, Determinants of infant and young child feeding practices by mothers in two rural districts of Sindh, Pakistan: a cross-sectional survey. International breastfeeding journal., 2017. 12(1): p. 40.

30. Adhikari M, Karkee R, Gavidia.T, Factors associated with early initiation of breastfeeding among Nepalese mothers: further analysis of Nepal Demographic and Health Survey, 2011. International breastfeeding journal, 2014. 9(21).

\section{Tables}

Table 1: Distribution of OBF with individual level variables among 0-5 month old children, Ethiopia 2016 $(n=1,087)$ 
I.

\begin{tabular}{|c|c|c|c|}
\hline variables & Category & Frequency & OBF (\%) \\
\hline \multirow[t]{2}{*}{ Sex of child } & Male & 532 & $227(42.7)$ \\
\hline & Female & 557 & $266(47.8)$ \\
\hline \multirow[t]{3}{*}{ Age categories of children } & $<2$ month & 353 & $214(60.6)$ \\
\hline & $2-3$ month & 352 & $187(53)$ \\
\hline & 4-5 month & 382 & $93(24)$ \\
\hline \multirow[t]{3}{*}{ Size of child at birth } & Large & 261 & $116(44.4)$ \\
\hline & Average & 467 & $220(47)$ \\
\hline & Small & 359 & $157(43.7)$ \\
\hline \multirow[t]{3}{*}{ Birth order } & $1^{\text {st }}$ & 242 & $87(35.9)$ \\
\hline & $2-4$ & 457 & $231(50.5)$ \\
\hline & Five and above & 388 & 175 (45) \\
\hline \multirow{3}{*}{ Mothers educational status } & No education & 642 & $286(44.5)$ \\
\hline & Primary education & 418 & $200(47.8)$ \\
\hline & Secondary and higher & 27 & $7(24)$ \\
\hline \multirow[t]{2}{*}{ Mothers occupation } & Not employed & 868 & $395(45.5)$ \\
\hline & Employed & 219 & $98(44.7)$ \\
\hline \multirow[t]{3}{*}{ Marital status } & Never married & 9 & $1(11)$ \\
\hline & Married/living together & 1,051 & $481(45.7)$ \\
\hline & Divorced/widowed/separated & 26 & $11(42.8)$ \\
\hline \multirow[t]{5}{*}{ Wealth index } & Poorest & 268 & $102(37.9)$ \\
\hline & Poor & 255 & $135(53)$ \\
\hline & Middle & 195 & $97(49.7)$ \\
\hline & Richer & 201 & $70(34.8)$ \\
\hline & Richest & 168 & $89(53)$ \\
\hline \multirow[t]{3}{*}{ Parity of the mother } & $1-2$ & 411 & 179 (43) \\
\hline & $3-4$ & 288 & $138(48)$ \\
\hline & Five and above & 388 & $176(45.4)$ \\
\hline \multirow[t]{4}{*}{ ANC utilization } & No ANC visit & 371 & $174(46.7)$ \\
\hline & 1 visit & 61 & $19(31.8)$ \\
\hline & $2-3$ visit & 310 & $151(48.7)$ \\
\hline & $>=4$ visits & 336 & $149(44)$ \\
\hline \multirow[t]{3}{*}{ Place of delivery } & Home & 672 & $308(45.8)$ \\
\hline & Health facility & 397 & $177(44.6)$ \\
\hline & Other & 18 & $8(44)$ \\
\hline \multirow[t]{2}{*}{ Mode of delivery } & Normal & 1,055 & $487(46)$ \\
\hline & Cesarean section & 32 & $6(17)$ \\
\hline \multirow[t]{3}{*}{ Husband education } & No education & 505 & $228(45)$ \\
\hline & Primary education & 384 & $187(48.5)$ \\
\hline & Secondary and higher & 162 & $66(40.7)$ \\
\hline \multirow[t]{2}{*}{ Husband occupation } & Not employed & 74 & $27(36.3)$ \\
\hline & Employed & 978 & $454(46.4)$ \\
\hline \multirow[t]{6}{*}{ Ethnicity } & Amhara & 235 & $113(48)$ \\
\hline & Oromia & 478 & $217(45.3)$ \\
\hline & Tigrie & 76 & $36(47.3)$ \\
\hline & Afar & 8 & $1(13)$ \\
\hline & Somalia & 48 & $10(20.8)$ \\
\hline & Others & 242 & $114(47)$ \\
\hline
\end{tabular}

ANC: Antenatal care

Table 2: Distribution of OBF with community level among 0-5 month old children, Ethiopia $2016(\mathrm{n}=1,087)$ 


\begin{tabular}{llll}
\hline II. & Category & Frequency & OBF (\%) \\
\hline Community media exposure & Low & 482 & $233(48.3)$ \\
& High & 605 & $260(43)$ \\
Community education & Low & 560 & $250(44.6)$ \\
& High & 527 & $243(46.1)$ \\
& Tigray & 76 & $36(47.5)$ \\
& Afar & 9 & $2(22.2)$ \\
& Amhara & 204 & $96(47)$ \\
& Oromo & 495 & $224(45.2)$ \\
& Somalia & 50 & $13(23.6)$ \\
& Benshangul & 12 & $6(50)$ \\
& SNNP & 207 & $102(49.2)$ \\
& Gambela & 2 & $1(50)$ \\
& Harare & 3 & $1(33.3)$ \\
Place of residence & AddisAbeba & 25 & $10(40)$ \\
& Dire Dawa & 4 & $2(50)$ \\
Community ANC & Urban & 124 & $57(46)$ \\
& Rural & 963 & $436(45)$ \\
Community poverty & Low & 514 & $242(47)$ \\
& High & 573 & $251(43.9)$ \\
& Low & 623 & $276(44.3)$ \\
& High & 464 & $217(46.7)$ \\
& Low & 532 & $233(43.8)$ \\
& High & 555 & $260(46.8)$ \\
\hline
\end{tabular}

$\mathrm{ANC}=$ Antenatal care

Table 3: Multivariable multilevel logistic regression analysis of individual and community level factors associated with OBF among 0-5 month old children, Ethiopia $2016(\mathrm{n}=1,087)$ 


\begin{tabular}{|c|c|c|c|c|}
\hline Variables & Category & $\begin{array}{l}\text { Model II } \\
\text { AOR }[95 \% C I]\end{array}$ & $\begin{array}{l}\text { Model III } \\
\text { AOR }[95 \% \mathrm{CI}]\end{array}$ & $\begin{array}{l}\text { Model IV } \\
\text { AOR }[95 \% \mathrm{CI}]\end{array}$ \\
\hline \multirow[t]{3}{*}{ Child age group } & $<2$ month & 1.00 & & \\
\hline & 2-3 month & $0.86(0.60-1.22)$ & & $0.85(0.59-1.21)$ \\
\hline & 4-5 month & $0.19(0.13-0.28) *$ & & $0.19(0.12-0.27) *$ \\
\hline \multirow[t]{5}{*}{ Wealth index } & Poorest & 1.00 & & \\
\hline & Poorer & $1.52(0.95-2.43)$ & & $1.38(0.85-2.26)$ \\
\hline & Middle & 1.68 (0.99- 2.86) & & $1.56(0.90-2.71)$ \\
\hline & Richer & $0.91(0.54-1.54)$ & & $0.91(0.52-1.59)$ \\
\hline & Richest & $2.16(1.27-3.70)^{*}$ & & 2.87(1.53- 5.43)* \\
\hline \multirow{2}{*}{ Mode of delivery } & None C/S & 1.00 & & \\
\hline & $\mathrm{C} / \mathrm{S}$ & $0.19(0.07-0.50) *$ & & $0.18(0.07-0.51) *$ \\
\hline \multirow{6}{*}{ Ethnicity } & Afar & 1.00 & & \\
\hline & Amhara & $7.39(2.87-19) *$ & & \\
\hline & Oromia & 4.93(2.17-11.19)* & & \\
\hline & Tigray & $6.89(2.48-19) *$ & & \\
\hline & Somalie & $2.14(0.92-5.05)$ & & \\
\hline & Others & 5.61(2.37-13.44)* & & \\
\hline \multirow[t]{11}{*}{ Region } & Addis ababa & & 1.00 & \\
\hline & Tigray & & $1.31(0.60-2.83)$ & $0.87(0.13-5.81)$ \\
\hline & Afar & & $0.29(0.11-0.73) *$ & $0.13(0.02-0.92)^{*}$ \\
\hline & Amhara & & $1.57(0.71-3.50)$ & $1.32(0.44-3.91)$ \\
\hline & Oromo & & $1.56(0.72-3.41)$ & $1.87(0.66-5.34)$ \\
\hline & Somalie & & $0.60(0.27-1.35)$ & $1.94(0.37-10.3)$ \\
\hline & Benshangul & & 1.74(0.76- 3.98) & $1.69(0.61-4.71)$ \\
\hline & SNNP & & $1.75(0.80-3.82)$ & $2.12(0.72-6.27)$ \\
\hline & Gambela & & $0.97(0.39,2.38)$ & $1.50(0.44-5.13)$ \\
\hline & Harare & & $0.85(0.34-2.11)$ & $0.74(0.24-2.29)$ \\
\hline & Dire Dawa & & $1.87(0.75-4.68)$ & $2.63(0.84-8.30)$ \\
\hline
\end{tabular}

*significant at $\mathrm{p}<0.05 \quad \mathrm{C} / \mathrm{s}=$ caesarian section

Table 4: Random effects and model fitness of individual and community level factors associated with optimal breastfeeding among 0-5 month old children, Ethiopia $2016(\mathrm{n}=1,087)$

\begin{tabular}{lllll}
\hline Random effect & Model I & Model II & Model III & Model IV \\
\hline Community variance (SE) & $0.797^{*}$ & $0.615^{*}$ & $0.399^{*}$ & $0.389 *$ \\
& $(0.274)$ & $(0.271)$ & $(0.219)$ & $(0.252)$ \\
ICC (\%) & 19.5 & 15.75 & 10.82 & 10.6 \\
\hline PCV (\%) & Reference & 22.8 & 49.9 & 51 \\
\hline Model fitness & Model I & Model II & Model III & Model IV \\
\hline Log likelihood & -718.445 & -629.651 & -689.84904 & -592.05634 \\
AIC & 1440.892 & 1309.315 & 1407.698 & 1280.113 \\
\hline
\end{tabular}

ICC: Intra-class correlation coefficient $\quad$ *significant at $\mathrm{p}<0.05$

PCV: Proportional Change in Community Variance

AIC (Akaike information criterion) 
Figures

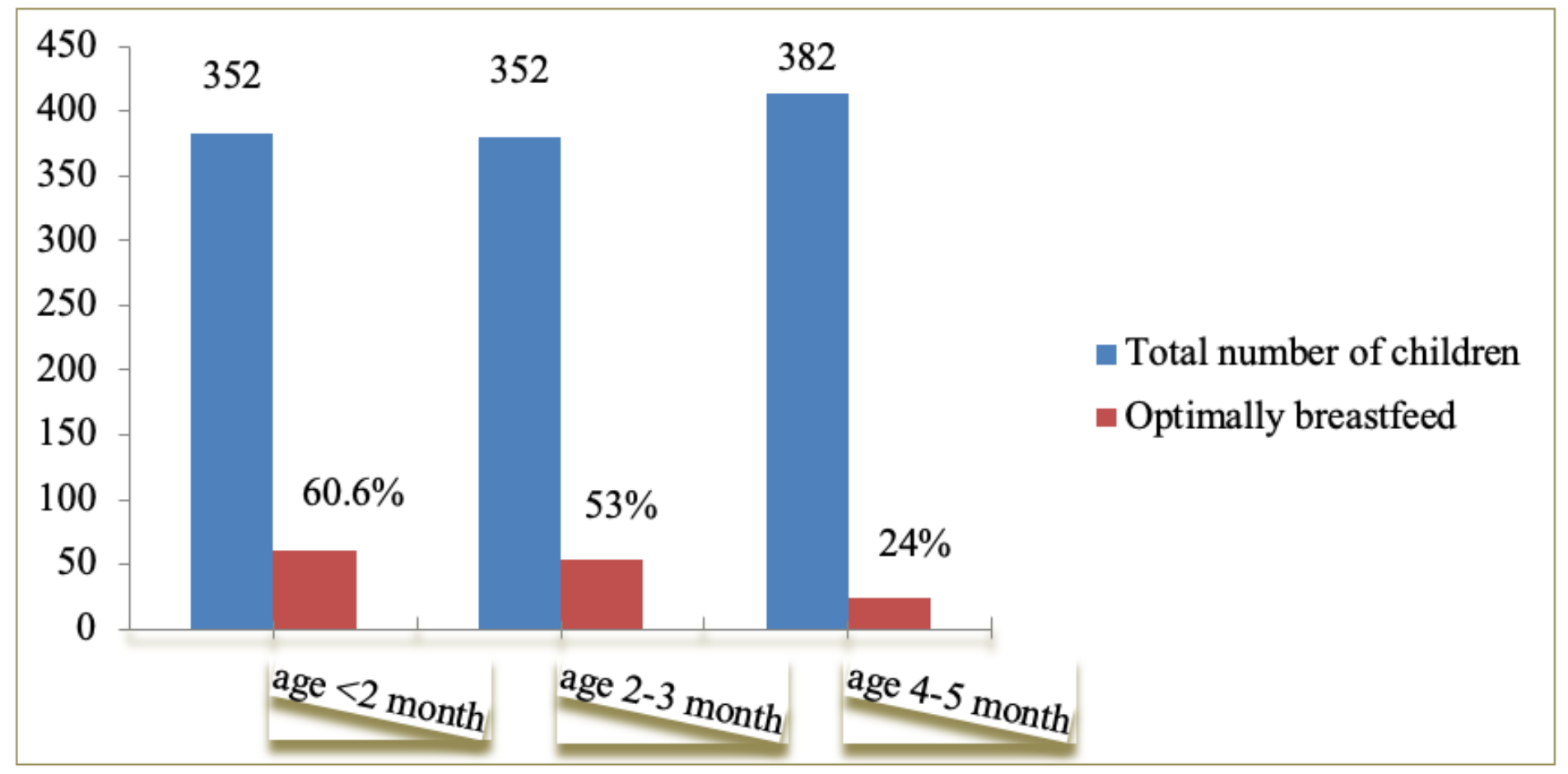

Figure 1

Age distribution of children who were optimal breastfeed among 0-5 month age, Ethiopia $2016(n=1,087)$ 


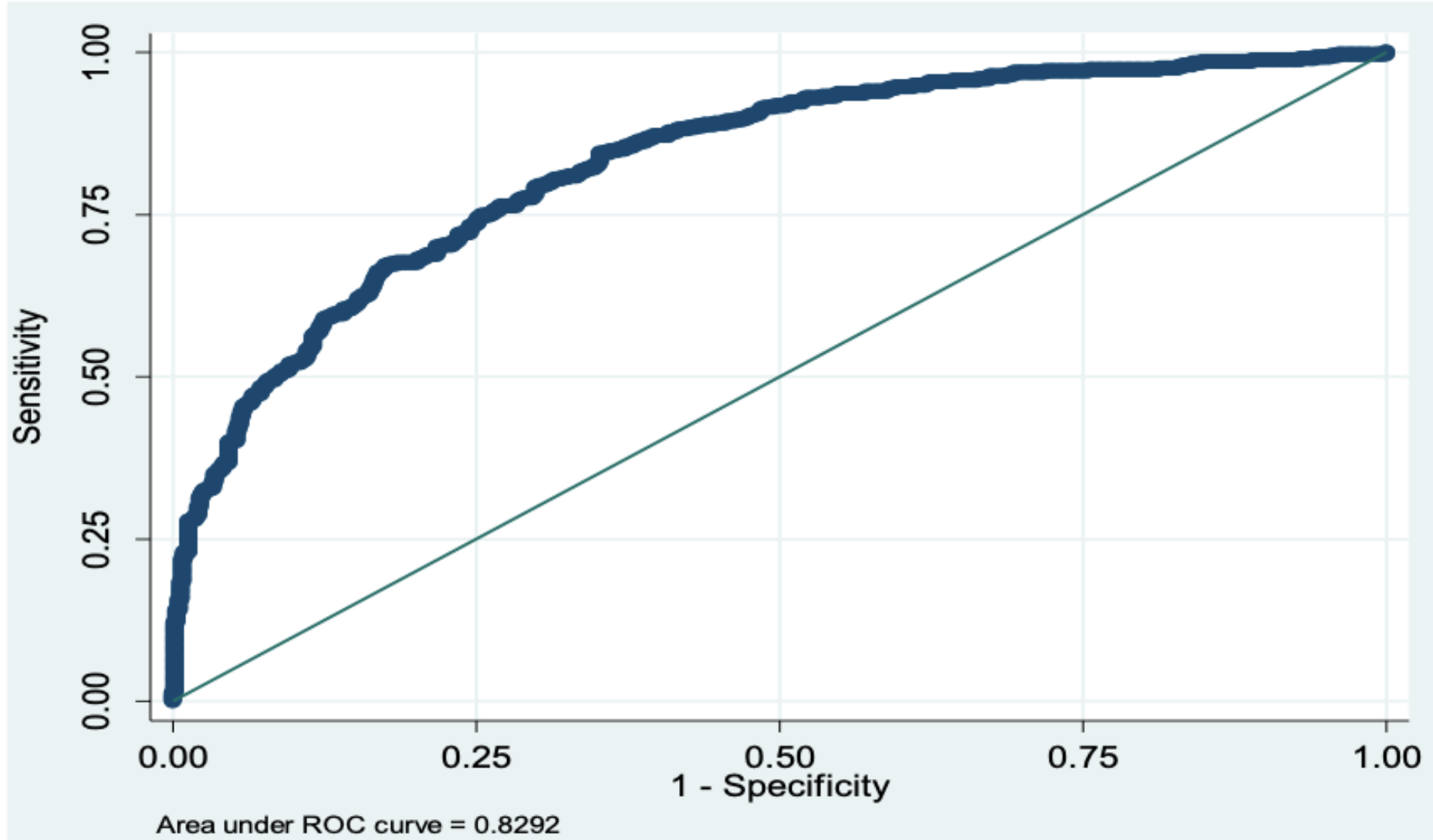

Figure 2

ROC model accuracy of individual and community-level factors associated with optimal breastfeeding among 0-5 month age children, Ethiopia 2016 